\title{
Rémy Boucharlat. "Qanat and Falaj: Polycentric and Multi-Period Innovations. Iran and the United Arab Emirates as Case Studies"
}

\section{Sébastien Gondet}

\author{
(2) OpenEdition \\ Journals \\ Édition électronique \\ URL : http://journals.openedition.org/abstractairanica/48569 \\ DOI : 10.4000/abstractairanica.48569 \\ ISBN : 1961-960X \\ ISSN : 1961-960X \\ Éditeur : \\ CNRS (UMR 7528 Mondes iraniens et indiens), Éditions de l'IFRI
}

Référence électronique

Sébastien Gondet, «Rémy Boucharlat. "Qanat and Falaj: Polycentric and Multi-Period Innovations. Iran and the United Arab Emirates as Case Studies" », Abstracta Iranica [En ligne], Volume 40-41 | 2019, document 4, mis en ligne le 30 octobre 2019, consulté le 25 avril 2021. URL : http://

journals.openedition.org/abstractairanica/48569; DOI : https://doi.org/10.4000/abstractairanica. 48569

Ce document a été généré automatiquement le 25 avril 2021.

Tous droits réservés 


\title{
Rémy Boucharlat. "Qanat and Falaj: Polycentric and Multi-Period Innovations. Iran and the United Arab Emirates as Case Studies"
}

\author{
Sébastien Gondet
}

\section{RÉFÉRENCE}

Rémy Boucharlat. "Qanat and Falaj: Polycentric and Multi-Period Innovations. Iran and the United Arab Emirates as Case Studies" in A.N. Angelakis, E. Chiotis, S. Eslamian, H. Weingartner (eds.). Underground Aqueducts Handbook. Boca Raton : CRC Press, 2017, p. 279-301.

1 Cet article est issu d'un volume de référence rassemblant des synthèses traitant des techniques d'adduction d'eau par aqueducs souterrains, correspondant pour l'Iran aux qanats. Au fil des 29 articles qui composent ce livre, ces ouvrages hydrauliques sont décrits et analysés de manière diachronique (depuis leur apparition au cours du $1^{\mathrm{er}}$ millénaire av. J.-C. jusqu'à l'époque moderne) et pluridisciplinaire (contributions de spécialistes, des hydrologues aux historiens). Ces techniques, souvent considérées comme des solutions durables d'exploitation les ressources hydriques en milieu aride, ont été et sont toujours utilisées sur l'ensemble des cinq continents. Un chapitre du livre est consacré à chacun des continents à l'exception du Moyen Orient qui, en tant que région d'origine de ces techniques concentrant un grand nombre de cas d'étude, fait l'objet d'un chapitre à part rassemblant à lui seul 9 articles. Parmi ceux-ci, deux sont consacrés plus spécifiquement à l'Iran. Un premier rédigé par des ingénieurs hydrauliciens iraniens décrit d'un point de vue général le fonctionnement des qanats, les avantages et les inconvénients de cette méthode traditionnelle d'irrigation dans le contexte géographique et culturel de l'Iran. Le second, dont il est question ici, traite des 
données archéologiques sur les qanats non seulement en Iran mais sur l'ensemble du pourtour du golfe Persique.

2 On a souvent voulu faire remonter l'origine du qanat à la période achéménide. Son invention aurait même pu contribuer la mise en valeur des territoires iraniens et donc participer à l'expansion territoriale perse. Cet article de synthèse, qui reprend et continue la réflexion au long cours de l'A. concernant l'apparition et la diffusion de la technique du qanat, a le mérite de tordre le cou de manière définitive à ce topos. A la lumière de l'ensemble des données archéologiques rassemblées et résumées dans cet article, il est très clair d'une part que cette technique a été développée bien avant la période achéménide, d'autre part que son apparition s'est faite de manière polycentrique.

3 Les plus vieux exemples de falaj, terme équivalent à qanat pour les pays de la péninsule Arabique, parfaitement datés du IX ${ }^{\mathrm{e}}$ s. av. J.-C. (Age du fer) par l'archéologie se trouvent aux Emirats Arabes Unis. Au cours des siècles qui suivirent, on retrouve çà et là des exemples de galeries drainantes, s'adaptant aux ressources hydrogéologiques régionales et reflétant des solutions techniques particulières, dans plusieurs régions depuis l'est de l'Iran jusqu'à la Libye. Il n'existe donc aucun indice de diffusion d'un modèle uniforme du qanat. Après une phase de déclin, cette technique va connaître une seconde phase de développement, spécifiquement en Iran cette fois-ci, à partir du milieu du $1^{\text {er }}$ millénaire ap. J.-C. et de la fin de l'empire sassanide. Les données archéologiques rejoignent en cela les données textuelles puisque la plus ancienne attestation de qanat ne remonte qu'au $\mathrm{XI}^{\mathrm{e}} \mathrm{s}$. ap. J-C. Si l'on met de côté les récentes datations absolues obtenues sur des déblais de creusement de puits de qanats dans le nord-est de l'Iran dont, d'après l'A., la validité reste à démontrer, on peut donc affirmer que le qanat n'est pas une invention uniquement iranienne et que le développement de cette technique en Iran s'effectue essentiellement aux cours des périodes médiévales.

\section{AUTEURS}

\section{SÉBASTIEN GONDET}

UMR 5133 CNRS-Université de Lyon 